\title{
Quantitated scintillation scanning for the measurement of lung perfusion
}

\author{
E. S. GARNETT AND B. A. GODDARD \\ From the Wessex Regional Department of Nuclear Medicine, Royal South Hants Hospital, Southampton \\ A N D \\ E. S. MACHELL AND W. M. MACLEOD \\ From Southampton Chest Hospital, Oakley Road, Southampton
}

\begin{abstract}
A method using quantitated lung scans is described for the accurate proportioning of lung perfusion. The results obtained by this method have been compared directly with those obtained from bronchospirometry, and a good correlation has been obtained $(r=+0.93)$.
\end{abstract}

The measurement of lung perfusion by bronchospirometry was first described by Björkman in 1934. The method is cumbersome and unpleasant for the patient, since it involves intratracheal intubation. Nevertheless, it is still a standard method for the measurement of individual lung perfusion. In 1964, Wagner, Sabiston, McAfee, Tow, and Stern described their preliminary findings with a new radioisotope lung scanning procedure. They injected macroaggregates of ${ }^{131} \mathrm{I}$ labelled human serum albumin into a peripheral vein, localized the accumulation of radioactivity in the lung with a Scintiscanner, and postulated that the concentration of radioactively labelled micro-emboli in the various parts of the lung was directly related to pulmonary blood flow.

In this study we have compared the blood flow in each lung, as determined by bronchospirometry, with the individual lung perfusion, as determined by a quantitative Scintiscanning procedure.

\section{MATERIALS AND METHODS}

Twenty patients suffering from carcinoma of the bronchus or bullous emphysema were studied.

Bronchospirometry was carried out with a double lumen Carlen's catheter connected to Godart Pulmotest spirometers filled with oxygen. The patients were sedated with haloperidol and the catheter was passed under local anaesthesia (one amethocaine lozenge followed by crico-thyroid injection of $10 \%$ cocaine and a laryngeal spray with $4 \%$ lignocaine).

Lung scans were performed using a Picker Magna Scanner V, with a 265 hole, 5 in. focus collimator. Human serum albumin, labelled with approximately $300 \mu \mathrm{Ci}{ }^{131} \mathrm{I}$, was macroaggregated by heating at its isoelectric point. Scans were made in both the prone and supine positions immediately after injection of the macroaggregates.
The quantity of radioactivity in each lung was $\vec{\bullet}$

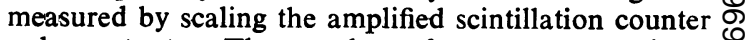
pulse output. The number of counts accumulated in successive $4-\mathrm{cm}$. horizontal strips was recorded, and activity profiles were constructed by plotting the counts accumulated in each $4-\mathrm{cm}$. strip on the ordinate against the mid-position of the strip in centimetres from the spine of the first thoracic vertebra $\mathbb{D}$ on the abscissa (Fig. 1). Activity profiles were con- $\stackrel{2}{\overrightarrow{7}}$ structed for each lung in both the prone and supine $\overrightarrow{0}$ positions. The sum of the areas under the activity profiles of the right lung were expressed as a percentage of the sum of the areas under the activity profiles of both lungs. This percentage represents the proportion of the dose of ${ }^{131} \mathrm{I}$ macroaggregated albumin which accumulates in the right lung.

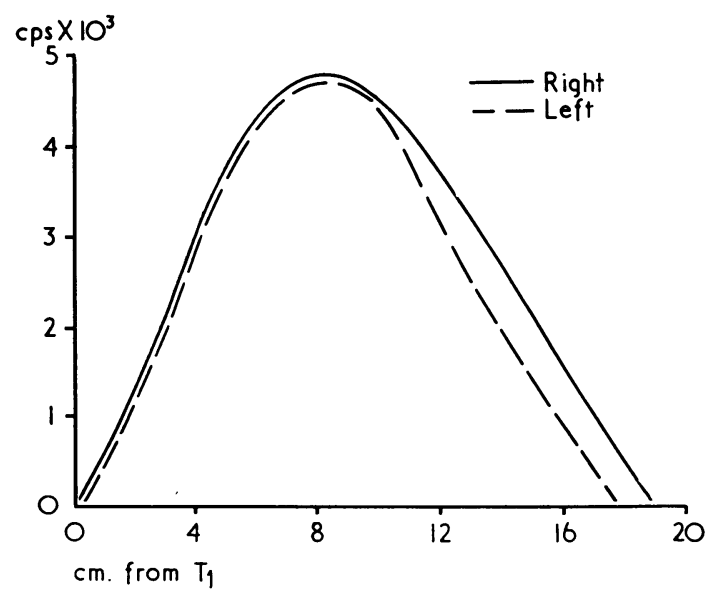

FIG. 1. Normal activity profiles of right and left lungs. Counts accumulated in successive 4-cm. horizontal strips on ordinate; distance of strip from spine of $T_{1}$ on abscissa. 


\section{RESULTS}

The percentage of the dose of ${ }^{131} \mathrm{I}$ macroaggregated albumin which accumulated in the right lung ranged from $10 \%$ to $83 \%$. The percentage oxygen uptake per minute in the right lung ranged from $20 \%$ to $86 \%$. Figure 2 shows

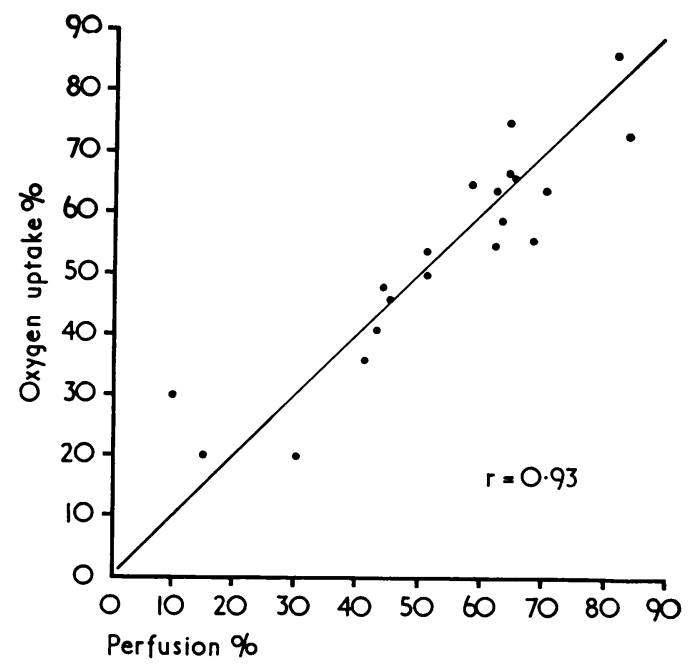

FIG. 2. Comparison between proportion of total lung perfusion in right lung obtained by quantitative lung scanning and bronchospirometry $(r=+0 \cdot 93)$.

the comparison between the results obtained for oxygen uptake and the percentage of the dose of ${ }^{13}{ }^{1}$ I macroaggregated albumin which accumulated in the right lung $(r=+0.93)$.

\section{DISCUSSION}

It will be seen from Fig. 2 and the $r$ value of +0.93 that a quantitated lung scan provides information about the relative proportion of lung perfusion which compares very favourably with that obtained by bronchospirometry, and these observations accord well with those of LopezMajano, Chernick, Wagner, and Dutton (1964), who obtained a good correlation between differential oxygen uptake and a semi-quantitative radioisotope lung scanning technique.

In 1960, Dyson, Hugh-Jones, Newbery, Sinclair, and West used ${ }^{15} \mathrm{O}$ with a half life of only 2 minutes for the determination of relative ventilation and perfusion in different regions of the lung. Since then ${ }^{133} \mathrm{Xe}$, with a half life of $5 \cdot 27$ days, has been used to measure regional ventilation and perfusion (Ball, Stewart, Newsham, and
Bates, 1962 ; Bentivoglio, Beerel, Bryan, Stewart, Rose, and Bates, 1963 ; Dollery and Gillam, 1963 ; Dawson, Kaneko, and McGregor, 1965), but until recently no direct comparisons have been made between overall lung perfusion measured with ${ }^{133} \mathrm{Xe}$ and bronchospirometry. Arborelius (1965) gave ${ }^{85} \mathrm{Kr}$ intravenously and compared the amount of ${ }^{85} \mathrm{Kr}$ exhaled from each lung during bronchospirometry. Arborelius' method was cumbersome, since it involved the collection of ${ }^{85} \mathrm{Kr}$ in Douglas bags, but the relationship between ${ }^{85} \mathrm{Kr}$ exhaled and oxygen uptake was good. In 1968 Miörner, using batteries of four scintillation counters positioned over the back and front of the chest, compared radiospirometry with ${ }^{133} \mathrm{Xe}$ with bronchospirometry and found good agreement.

In our studies, using quantitated lung scans following the administration of ${ }^{131}$ I labelled microemboli, information was obtained not only about the relative perfusion of each lung but also about the distribution of perfusion within the lungs, since a rectilinear scanner with a resolution of 2 $\mathrm{cm}$. was used. Thus, it was sometimes possible to obtain information about local perfusion from the scan which was not always obtainable from pulmonary angiography. Such detailed information cannot be obtained from ${ }^{133} \mathrm{Xe}$ studies even when batteries of scintillation counters are used, but Newhouse and his co-workers (Newhouse, Wright, Ingham, Archer, Hughes, and Hopkins, 1968) have recently gone some way towards achieving this by quantitating the regional output from a gamma camera using ${ }^{135} \mathrm{Xe}$.

\section{REFERENCES}

Arborelius, M. (1965). $\mathrm{Kr} 85$ in the study of pulmonary circulation during bronchospirometry. Scand. J. clin. Lab. Invest., 17, 253.

Ball, W. C., Stewart, P. B., Newsham, L. G. S., and Bates, D. V (1962). Regional pulmonary function studied with Xenon ${ }^{133}$ J. clin. Invest., $41,519$.

Bentivoglio, L. G., Beerel, F., Bryan, A. C., Stewart, P. B., Rose, B. and Bates, D. V. (1963). Regional pulmonary function studied with 133-Xenon in patients with bronchial asthma. Ibid., 42, 1193.

Björkman, S. (1934). Bronchospirometrie; eine klinische Methode, die Funktion der menschlichen Lungen getrennt und gleichzeitig zu untersuchen. Acta med. scand., Suppl. 56.

Dawson, A., Kaneko, K., and McGregor, M. (1965). Regional lung function in patients with mitral stenosis studied with Xenon ${ }^{133}$ during air and oxygen breathing. J. clin. Invest., 44, 999.

Dollery, C. T., and Gillam, P. M. S. (1963). The distribution of blcod and gas within the lungs measured by scanning after administration of ${ }^{133}$ Xe. Thorax, $18,316$.

Dyson, N. A., Hugh-Jones, P., Newbery, G. R., Sinclair, J. D., and West, J. B. (1960). Studies of regional lung function using radioactive oxygen. Brit. med. J., 1, 231 .

Lopez-Majano, V., Chernick, V., Wagner, H. N., and Dutton, R. E. (1964). Comparison of radioisotore scanning and differential oxygen uptake of the lungs. Radiology, 83, 697.

Miörner, G. (1968). ${ }^{133}$ Xe-radiospirometry. Scand. J. resp. Dis., Suppl. 64.

Newhouse, M. T., Wright, F. J., Ingham, G. K., Archer, N. P., Hughes, L. B., and Hopkins, O. L. (1968). Use of scintillation camera and 135Xence for study of topographic pulmorary function. Resp. Physiol., 4, 141.

Wagner, H. N., Sabiston, D. C., McAfee, J. G., Tow, D., and Stern, H. S. (1964). Diagnosis of massive pulmonary embolism in ran by radioisotope scanning. New Engl. J. Med., 271, 377. 